\title{
STRATEGI PROMOSI PERPUSTAKAAN SEKRETARIAT JENDERAL DEWAN PERWAKILAN DAERAH REPUBLIK INDONESIA
}

\author{
Sigit Setyo Wibowo ${ }^{1}$, Neneng Komariah ${ }^{2}$, Nuning Kurniasih ${ }^{3}$ \\ ${ }^{1}$ Angkasa Pura Support, ${ }^{2,3}$ Program Studi Ilmu Perpustakaan Fikom Unpad \\ ${ }^{1}$ sigitsetyo80@yahoo.com ${ }^{2}$ neneng.komariah@unpad.ac.id, ${ }^{3}$ nuningkurniasih@yahoo.com
}

\begin{abstract}
The purpose of the research is to discover the promotion strategy carried out by the library of the Regional Representative Council of the Republic of Indonesia (DPD RI). To obtain that purpose, the method used is qualitative research with descriptive approach and the informant used is the librarian in the Regional Representative Council of the Republic of Indonesia. The data were acquired through interviews, observations, library research and documentation. The result of this research represents that in running promotional strategy for their library, the Regional Representative Council of the Republic of Indonesia pass through several stages of environmental analysis, formulation, implementation and the evaluation. According to this whole series of analysis, we are able to see the implementation of the promotion for the Regional Representative Council of the Republic of Indonesia's library. And there are various media to promote the library, such as brochures, personal selling (door to door and direct presentation), direct marketing (Delivery Order, DPD RI's library website, and Facebook account creation).
\end{abstract}

Keywords: Promotion, Marketing Strategy, Library of DPD RI.

ABSTRAK - Tujuan dari penelitian ini adalah untuk menemukan strategi promosi yang dilakukan oleh perpustakaan dari Dewan Perwakilan Daerah Republik Indonesia (DPD RI). Untuk mendapatkan tujuan tersebut, metode yang digunakan adalah penelitian kualitatif dengan pendekatan deskriptif dan informan yang digunakan adalah pustakawan di Dewan Perwakilan Daerah Republik Indonesia. Data diperoleh melalui wawancara, observasi, studi pustaka dan dokumentasi. Hasil penelitian ini menyatakan bahwa dalam menjalankan strategi promosi untuk perpustakaan mereka, Dewan Perwakilan Daerah Republik Indonesia melewati beberapa tahap analisis lingkungan, formulasi, implementasi dan evaluasi. Menurut seluruh rangkaian analisis, kita dapat melihat pelaksanaan promosi untuk Dewan Perwakilan Daerah Republik perpustakaan di Indonesia. Dan ada berbagai media untuk mempromosikan perpustakaan, seperti brosur, personal selling (door to door dan presentasinya langsung), pemasaran langsung (Delivery Order, website perpustakaan DPD RI, dan pembuatan akun Facebook).

Kata Kunci: Promosi, Strategi Marketing, Perpustakaan DPR RI

\section{PENDAHULUAN}

Strategi promosi merupakan awal dalam rangka mengenalkan produk kepada konsumen dan ini menjadi sangat penting karena berhubungan dengan keuntungan-keuntungan yang akan diperoleh perusahaan. Strategi promosi akan bisa berguna dengan optimal bila didukung dengan perencanaan yang terstruktur dengan baik.

Perpustakaan khusus harus dapat merancang strategi promosi yang tepat dalam mencapai tujuan perpustakaan. Salah satu tujuan perpustakaan adalah dapat menarik minat pengunjung perpustakaan untuk datang ke perpustakaan tersebut. Oleh karena itu untuk menarik perhatian pengunjung perpustakaan harus bisa menerapkan suatu strategi pemasaran yang tepat sesuai dengan kondisi yang dihadapi. Keberhasilan strategi pemasaran dipengaruhi oleh beberapa faktor, salah satunya yaitu dengan memilih promosi yang tepat dalam memasarkan jasa.

Menurut Sutarno $(2006,68)$ mengungkapkan bahwa Perpustakaan khusus berada pada lembaga-lembaga pemerintahan dan swasta. Perpustakaan tersebut diadakan sebagai sumber informasi dan ilmu pengetahuan yang berkaitan baik langsung maupun tidak langsung dengan instansi induknya. 
Promosi perpustakaan merupakan rangkaian kegiatan perpustakaan yang dirancang agar masyarakat mengetahui manfaat sebuah perpustakaan melalui koleksi, fasilitas, dan produk / layanan yang disediakan. Seperti yang diungkapkan oleh (Winardi 1981, 147) bahwa Promosi adalah upaya-upaya suatu perusahaan untuk mempengaruhi para pembeli agar mereka mau membeli produk yang dihasilkan perusahaan atau menggunakan jasa yang disediakan.

Perpustakaan yang memiliki kelembagaan seperti Perpustakaan Sekretariat Jenderal DPD RI yang baru didirikan pada awal tahun 2008, diperuntukan bagi anggota DPD RI dan seluruh pegawai di lingkungan Sekretariat Jenderal DPD RI dalam rangka mendukung tugas dan fungsi DPD RI. Perpustakaan ini merupakan gagasan dari Sekretariat Jenderal DPD RI yang mana lembaga pemerintahan harus memiliki suatu perpustakaan. Tempatnya masih belum berdiri sendiri dalam artian ruangannya masih bergabung dengan sub bagian data dan informasi. Koleksi yang ada baru sekitar kurang lebih 2000 koleksi yang sebagian koleksinya mengenai ilmu sosial, ilmu politik, dan peraturan perundang-undang.

Perpustakaan Sekretariat Jenderal DPD RI didukung oleh pustakawan dan tenaga administrasi yang memiliki kecakapan dalam pengelolaan perpustakaan, untuk menunjang kelancaran operasionalnya perpustakaan didukung sarana dan prasarana berupa ruangan dengan ukuran 7,9 $\mathrm{m} \mathrm{x}$ 7,9 m yang dilengkapi dengan lemari buku, meja dan kursi baca, komputer, OPAC (Online Public Access Cataloging) adalah sarana penelusuran informasi mengenai koleksi yang ada di perpustakaan dengan menggunakan terminal komputer, akses internet dan ruang baca yang terintegrasi dengan ruang koleksi.

Melihat promosi yang dilakukan oleh Perpustakaan Sekretariat Jenderal DPD RI cukup menarik. Penulis melihat Perpustakaan Sekretariat Jenderal DPD RI dalam mempromosikannya terdapat dua bagian yaitu lingkup internal dan lingkup eksternal. Bagian lingkup internal seperti anggota DPD RI dan para pegawai staf di lingkungan Sekretariat Jenderal DPD RI, sedangkan untuk lingkup eksternal di luar lingkup internal atau diluar Sekretariat Jenderal DPD RI.

Kegiatan promosi dalam lingkup internal, Pustakawan atau para Staf DPD RI ini melakukan sosialisasi dengan membagikan selebaran kertas dalam bentuk pengumuman, dengan target ke unit kerja dan anggota Dewan DPD RI. Selain itu juga, berpartisipasi dalam acara atau kegiatan yang biasa diadakan oleh DPD RI, Kegiatan orientasi pengenalan perpustakaan bagi pegawai baru DPD RI, dan Membuat surat resmi ke bagian-bagian DPD RI.

Kegiatan promosi dalam lingkup eksternal, pustakawan dan para staf DPD RI mengikuti kegiatan forum perpustakaan khusus Lembaga Negara dan Kementrian, forum antar parlemen khusus (MPR, DPR dan DPD), kegiatan seminar, kegiatan diklat baik Nasional maupun Internasional. Kegiatan forum ini hanya mencakup pustakawan dan dengan adanya kegiatan-kegiatan penting tersebut, pustakawan dan para staf perpustakaan DPD RI bertindak dalam melakukan promosi perpustakaan dengan cara bersosialisasi 
dan menjalin kerjasama kepada Perpustakaan DPD RI dalam Intern Library Loan, untuk itu penulis tertarik untuk mengetahui lebih dalam tentang strategi promosi yang ada di Perpustakaan Sekretariat Jenderal DPD RI.

\section{TINJAUAN PUSTAKA}

Strategi promosi adalah perencanaaan, implementasi, dan pengendalian komunikasi dari suatu organisasi kepada para konsumen dari sasaran lainnya (Cravens 1998, 77). Menurut J. David Hunger \& Thomas L. Wheelen (2004), proses manajemen strategis meliputi empat elemen dasar, yaitu : (1). Pengamatan lingkungan; pengamatan lingkungan terdiri dari analisis eksternal dan analisis internal. Analisis eksternal terdiri dari variabel-variabel (kesempatan dan ancaman) yang berada diluar organisasi dan tidak secara khusus ada dalam pengendalian jangka pendek dari manajemen puncak. Sedangkan analisis internal terdiri dari variabel-variabel (kekuatan dan kelemahan) yang ada didalam organisasi tetapi biasanya tidak dalam pengendalian jangka pendek dari manajemen puncak.; (2) Perumusan strategi: perumusan strategi adalah pengembangan rencana jangka panjang untuk manajemen efektif dari kesempatan dan ancaman lingkungan, dilihat dari kekuatan dan kelemahan perusahaan.; (3) Implementasi strategi: implementasi strategi adalah proses dimana manajemen mewujudkan strategi dan kebijakannya dalam tindakan melalui pengembangan program, anggaran, dan prosedur.; (4) Evaluasi dan pengendalian adalah proses yang melaluinya aktivitas-aktivitas perusahaan dan hasil kinerja dimonitor dan kinerja sesungguhnya dibandingkan dengan kinerja yang diinginkan.

\section{METODE PENELITIAN}

Metode penelitian yang digunakan adalah metode penelitian kualitatif. Menurut Sugiyono $(2010,1)$ metode penelitian kualitatif adalah : "Metode penelitian yang digunakan untuk meneliti pada kondisi obyek yang alamiah, (sebagai lawannya eksperimen) dimana peneliti adalah sebagai instrument kunci, teknik pengumpulan data dilakukan secara triangulasi (gabungan), analisis data bersifat induktif, dan hasil penelitian kualitatif lebih menekankan makna dari pada generalisasi."

Penelitian ini juga menggunakan studi deskriptif. Menurut Sugiono (2005, 21) memberikan deskriptif sebagai berikut : "Metode deskriptif dapat diartikan sebagai prosedur pemecahan masalah yang diselidiki dengan menggambarkan/melukiskan keadaan subjek/objek penelitian (seseorang, lembaga, masyarakat dan lainlain) pada saat sekarang berdasarkan fakta-fakta yang tampak, atau sebagaimana adanya". Jadi penelitian yang digunakan dalam penelitian ini adalah metode kualitatif deskriptif karena pada penelitian ini hanya bertujuan untuk melukiskan atau mendeskripsikan secara faktual dan cermat.

\section{HASIL DAN PEMBAHASAN}

1. Analisis Internal Lingkungan Perpustakaan Sekretariat Jenderal DPD RI. Segi koleksi Perpustakaan Sekretariat Jenderal DPD RI memang memiliki kekuatan karena koleksinya menyangkut Ilmu Politik, Hukum, Demokrasi terutama Peraturan Perundang-undangan yang menyangkut tentang MPR, DPR, DPD RI. Banyak permintaan dari karyawan (user) dalam koleksi yang dimiliki oleh perpustakaan karena 
kebanyakan dari karyawan masih banyak yang masih meneruskan pendidikannya. Trend koleksi dalam permintaan oleh anggota atau karyawan DPD RI kebanyakan dari diklat sosial, politik, dan ekonomi. Menurut pembaca, Perpustakaan DPD RI ini dinilai sangat baik dalam memiliki bahan pustakanya.

2. Letak perpustakaan DPD RI berada di gedung B lantai 2 dan satu ruangan dengan ruangan Sub data informasi DPD RI. Perpustakaan DPD RI berdekatan dengan ruang rapat yang membuat perpustakaan ini makin sering di kunjungi oleh anggota atau karyawan DPD RI setelah rapat tersebut telah selesai. Dari segi letak ruangan perpustakaan terintegrasi dengan ruang kerja karyawan yang membuat karyawan DPD RI dapat melakukan pelayanan terhadap pengunjung perpustakaan. Keramahan sangat diperlukan karena untuk kesan pertama dan selanjutnya ketika pengunjung datang agar mereka bersedia datang untuk seterusnya.

3. Staff perpustakaan DPD RI menganggap bahwa sumber daya manusia di perpustakaan sudah cukup baik dan berkompeten karena mereka sudah berpengalaman di bidang perpustakaan. Selain itu mereka merasa cukup dengan jumlah staff yang ada di perpustakaan DPD RI. Dengan sumber daya manusia yang ada di perpustakaan DPD RI, merekapun menilai bahwa sumber daya manusia yang ada saat ini menjadi suatu kekuatan diperpustakaan. Dengan jumlah 4 staff ahli diperpustakaan DPD RI yang ada, mereka semua mampu memenuhi tugas-tugas yang ada di perpustakaan DPD RI dengan baik.

\section{Selain kekuatan (Strength) Perpustakaan} Sekretariat Jenderal DPD RI juga mempunyai kelemahan (Weakness). Untuk sumber daya manusia di perpustakaan DPD RI, peneliti menilai sangat minim karena mereka bekerja tidak fokus pada bidang keahliannya masingmasing. Jumlah staff yang ada di perpustakaan DPD RI menurut peneliti harus di tambah jumlah staffnya dengan jobdesk yang di pegang oleh masing-masing staff dan sesuai dengan jobdesknya. Dari segi kapasitas ruang yang kurang begitu besar, dimana perpustakaan DPD RI ini bergabung dengan ruangan sub data informasi yang membuat sebagian pengunjung tidak mengetahui keberadaan perpustakaan tersebut. Ruang koleksi dengan ruang pustakawan kurang terintegerasi dengan baik, serta ruang baca yang kurang. Banyak sekali yang meminjam buku tetapi tidak di baca di perpustakaan, kebanyakan bukunya dibawa oleh pembaca ke ruang kerjanya. Ini dikarenakan ruangan yang sangat minim sekali. Sebagai pustakawan pun sangat kurang nyaman karena tidak memiliki ruangan khusus bagi pustakawannya ini menyebabkan dapat mengganggu kinerja pustakawan dalam menjalani tugasnya.

5. Analisis Eksternal Lingkungan Perpustakaan Sekretariat Jenderal Dewan Perwakilan Daerah Republik Indonesia. Sama seperti analisis internal, analisis eksternal juga dibutuhkan perusahaan. Analisis eksternal untuk menentukan peluang (Opportunity) dan ancaman (Threat) Perpustakaan Sekretariat Jenderal DPD RI di pasar sasarannya.

Peluang dari Perpustakaan Sekretariat Jenderal DPD RI sendiri adalah buku merupakan sumber informasi bagi anggota dan karyawan Sekreta- 
riat Jenderal DPD RI. Selain itu koleksi yang disediakan oleh perpustakaan Sekretariat Jenderal DPD RI adalah sebagian atas permintaan dari anggota dan karyawan Sekretariat Jenderal DPD RI dalam memenuhi kebutuhan informasi bagi mereka. Mendirikan perpustakaan khusus seperti Perpustakaan Sekretariat Jenderal DPD RI di instansi parlemen seperti ini merupakan peluang (Opportunity) yang sangat bagus untuk kebutuhan anggota dan karyawan Sekretariat Jenderal DPD RI. Apalagi melihat bahwa sebagian mereka masih meneruskan pendidikannya dengan masing-masing ilmu yang berkaitan dengan ilmu politik, sosial, hukum dan ilmu lainnya. Seperti halnya perpustakaan, Perpustakaan Sekretariat Jenderal DPD RI juga memiliki fungsi rekreasi, Perpustakaan Sekretariat Jenderal DPD RI bisa menjadi alternatif untuk berekreasi dan mendapat hiburan bagi pengunjung khususnya anggota atau karyawan Sekretariat Jenderal DPD RI yang mungkin jenuh akan pekerjaan masing-masing dan membutuhkan hiburan.

Ancaman (Threat) dari perpustakaan Sekretariat Jenderal DPD RI sendiri adalah keberadaaan perpustakaan khusus lainnya seperti perpustakaan DPR RI dan MPR RI. Penulis melihat dari kedua perpustakaan tersebut yang menjadi ancaman yaitu perpustakaan DPR RI karena perpustakaan DPR RI menurut penulis sangat baik dalam pengelolaannya. Selain itu dari segi letak ruangan yang strategis dan ruangan yang cukup luas, membuat Customer dapat mengunjunginya dengan mudah dan sering sekali berkunjung ke perpustakaan DPR RI.
6. Perumusan Strategi Promosi Perpustakaan

Sekretariat Jenderal Dewan Perwakilan Daerah Republik Indonesia. Seperti yang dibahas pada Bab II perumusan strategi adalah pengembangan rencana jangka panjang untuk manajemen efektif dari kesempatan dan ancaman lingkungan, dilihat dari kekuatan dan kelemahan perusahaan. Perpustakaan Sekretariat Jenderal DPD RI sendiri sudah menganalisis kesempatan dan ancaman lingkungan serta kekuatan dan kelemahan Perpustakaan Sekretariat Jenderal DPD RI sendiri. Perumusan strategi meliputi menentukan misi perusahaan, menentukan tujuan-tujuan yang dapat dicapai, pengembangan strategi, dan penetapan pedoman kebijakan, dalam hal ini tentu yang berkaitan dengan strategi promosi. Meningkatkan minat baca anggota dan karyawan disekitar wilayah instansi parlemen adalah misi utama perpustakaan Sekretariat Jenderal DPD RI mendirikan perpustakaan tersebut. Sekretariat Jenderal DPD RI merupakan lembaga pemerintahan, itu menjelaskan bahwa memang daerah pemerintahan sangat jarang tempat hiburan, perpustakaan Sekretariat Jenderal DPD RI hadir sebagai alternatif hiburan masyarakat sekitar parlemen pemerintahan terutama anggota dan karyawan Sekretariat Jenderal DPD RI. Perpustakaan DPD RI ingin mengikutsertakan dirinya untuk membantu minat baca di masyarakat pemerintahan khususnya anggota dan karyawan di instansi Sekretariat Jenderal DPD RI.

7. Pelaksanaan Strategi Promosi Perpustakaan Sekretariat Jenderal Dewan Perwakilan Daerah Republik Indonesia. Dalam pelaksanaan strate- 
gi promosi ini, Perpustakaan Sekretariat Jenderal DPD RI telah lebih dahulu melakukan beberapa tahap hingga akhirnya memutuskan untuk melaksanakan program promosinya, seperti dengan melihat dari segmentasi pasar, target pasar, dan positioning produk dari Perpustakaan Sekretariat Jenderal DPD RI dengan melihat juga analisis SWOT perpustakaan Sekre- tariat Jenderal DPD RI. Dengan mempertimbangkan hal-hal tersebut, Perpustakaan Sekretariat Jenderal DPD RI memilih media-media yang sesuai dipakai untuk program promosinya. Berikut hasil wawancara dengan Ibu Khairunisa Fathonah sebagai pustakawan mengenai media promosi yang digunakan untuk mendukung strategi promosi yang dijalankan dari awal perpustakaan Sekretariat Jenderal DPD RI berdiri hingga sekarang, "Kita selalu memakai sistem brosur, man to man sama door to door. Kenapa kita masih mempertahankan hal itu, karena lebih nyampe ke orang kalau orang membaca brosurnya, itu strategi promosi, dari pada kita memakai spanduk yang ibaratnya kita baca selintas saja (inget ga ya bacaannya tadi apa ya), kalau brosur sebenarnya sih belum begitu menarik tapi setidaknya ketika mereka dapat dibaca dulu isinya atau tempatnya dimana.keterangan lebih jelasnya tentang perpustakaan ada di brosur tersebut, pastinya akan membuat si yang baca brosur itu tahu sedikit tentang profil perpustakaan di brosur tersebut" (Hasil wawancara tanggal 21 Februari 2014).
Brosur digunakan perpustakaan Sekretariat Jenderal DPD RI setiap bulannya, media ini berfungsi sebagai periklanan infomatif dan persuasif. Di mulai dari halaman depan terdapat gambar perpustakaan Sekretariat Jenderal DPD RI dengan logo instansi DPD RI. Di dalam brosur ini terdapat profil perpustakaan Sekretariat Jenderal DPD RI mulai dari visi dan misi perpustakaan, Motto dan beberapa maklumat dari perpustakaan Sekretariat Jenderal DPD RI.

\section{SIMPULAN}

Berdasarkan pembahasan yang telah dipaparkan pada bab IV maka kesimpulan dari Strategi Promosi Perpustakaan Sekretariat Jenderal DPD RI adalah sebagai berikut:

(1) Perpustakaan Sekretariat Jenderal DPD RI dalam pengamatan lingkungannya terdiri dari dua jenis analisis yaitu internal dan eksternal. Dalam analisis lingkungan internal dan eksternal, perpustakaan Sekretariat Jenderal DPD RI menggunakan analisis SWOT, yang terdiri dari kekuatan (Strenght), kelemahan (Weakness), peluang (Opportunity), dan ancaman (Threat). Dari analisis SWOT yang digunakan oleh perpustakaan Sekretariat Jenderal DPD RI ini memiliki pembahasan masing-masing.;

(2) Perumusan strategi di perpustakaan Sekretariat Jenderal DPD RI ini meliputi misi perpustakaan, menentukan tujuan-tujuan yang ingin dicapai oleh perpustakaan, pengembangan strategi dan penetapan pedoman kebijakan, dalam hal ini berkaitan dengan strategi promosi. Dari perumusan strategi tersebut maka dapat dijelaskan bahwa misi dari perpustakaan Sekretariat Jenderal DPD RI yaitu meningkatkan minat baca anggota 
dan karyawan di sekitar wilayah instansi parlemen. Menentukan segmentasi pasar, target pasar dan positioning perpustakaan merupakan perumusan strategi yang dilakukan oleh perpustakaan Sekretariat Jenderal DPD RI. Jadi dari perumusan yang telah di tentukan ini sudah berkaitan dari misi perpustakaan tersebut.;

(3) Pelaksanaan strategi promosi perpustakaan Sekretariat Jenderal DPD RI dilakukan melalui: mass selling yang terdiri dari periklanan (dengan media yang masih digunakan yaitu brosur), promosi penjualan (Delivery Order, stiker Perpustakaan Sekretariat Jenderal DPD RI), penjualan personal (dilakukan dengan door to door, dan presentasi langsung), pemasaran langsung (dilakukan melalui situs pustaka.dpd.go.id, angket dan facebook);

(4) Evaluasi yang dilakukan oleh perpustakaan Sekretariat Jenderal DPD RI yaitu evaluasi yang ditujukan secara umum terhadap setiap alat promosi yang digunakan oleh perpustakaan Sekretariat Jenderal DPD RI dalam hal menarik pengunjung untuk berkunjung ke perpustakaan tersebut. Untuk saat ini media yang sangat berperan dalam mempromosikan perpustakaan Sekretariat Jenderal DPD RI yaitu media brosur. Media ini dalam evaluasinya harus memiliki tampilan baik gambar, isi maupun warna yang menarik untuk pembacanya nanti. Selain itu media yang harus dimanfaatkan yaitu media online seperti media Facebook dan situs perpustakaan Sekretariat Jenderal DPD RI. Evaluasi yang harus di perhatikan dalam media ini harus digunakan sebaik mungkin dalam hal mempromosikan perpustakaan, jangan sampai digunakan dalam yang bersangkutan dengan hal lain.

\section{DAFTAR PUSTAKA}

Basuki, Sulistyo. (1993). Pengantar Ilmu Perpustakaan, Jakarta: Gramedia Pustaka Utama.

Cravens W David. (1998). Pemasaran Strategi. Jakarta : Erlangga.

Hunger, J. David; Wheelen, Thomas L. (2003). Manajemen Strategis; alih bahasa Julianto Agung S. Yogyakarta: Andi Yogyakarta.

J. David Hunger \& Thomas L. Wheelen. (2004). Strategic Management and Business Policy, 9th Edition. Pearson : Prentice Hall.

Kotler, Philip. (2002). Manajemen Pemasaran. Jakarta; PT. Indeks.

Mulyana, Deddy. (2001). Metodologi Penelitian Kualitatif: Paradigma Baru Ilmu Komunikasi dan Ilmu Sosial Lainnya. Bandung: Remaja Rosda Karya.

Perpustakaan Sekretariat Jenderal Dewan Perwakilan Daerah Republik Indonesia.: www.Pustaka. DPD.go.id Diakses pada tanggal 20 Juli 2013 pukul 22:30.

Sugiyono. (2005). Memahami Penelitian Kualitatif. Bandung: ALFABET.

Sutarno NS. (2006). Perpustakaan dan Masyarakat. CV. Sagung Seto : Jakarta

Tjiptono, Fandy. (2001). Strategi Pemasaran. Yogyakarta : Andi Yogyakarta.

Winardi. (1989). Aspek-aspek Bauran Pemasaran (Marketing Mix). Bandung: CV Mandar Maju.

Universitas Sumatera Utara, (2009). Pengertian Perpustakaan Khusus. Dikutip dari: http:// repository.usu.ac.id/bitstream/123456789/28 669/2/Chapter\%20II.pdf diakses pada tanggal 5 februari 2014 pukul 21:00.

Winardi. (1981). Manajemen Pemasaran. CV Maju Mundur: Bandung.

Yusup, Pawit M. (1991). Mengenal Dunia Perpustakaan dan informasi. Bandung : Rineka Cipta. 
